\title{
O CORISTA EUROPEU: TRADUÇÃO DE UM TEXTO ANÔNIMO, EM LÍNGUA GERAL DA AMAZÔNIA, DO SÉCULO XVIII.
}

Eduardo de Almeida Navarro*

O texto que traduzimos abaixo faz parte de um manuscrito anônimo guardado na Biblioteca Nacional de Portugal, em Lisboa, sob o número 569 e intitulado Vocabulário da Língoa, em Língua Geral Amazônica do século XVIII. Está ainda inédito.

Tal manuscrito inclui alguns interessantes textos, um dos quais, intitulado "Lida dos missionários com os sertanejos", que narra a vida numa missão religiosa católica às margens de um rio amazônico, foi traduzido e publicado por nós na Revista USP, no ano de 2008. Traduzimos, agora, mais um dos textos insertos no referido manuscrito.

Revelam-se, então, interessantes aspectos do dia-a-dia da vida missionária no século XVIII, a saber, o relacionamento nem sempre muito fácil dos missionários entre si, que tomavam a seus cuidados a educação de seminaristas muito novos, inclusive nascidos fora do Brasil, como é o caso do autor deste texto, que se afirma um "coris ta europeu". Este fala de suas travessuras durante o período de sua formação na ordem religiosa, algo bem sui generis e raramente visto em textos de missionários do período colonial brasileiro.

\footnotetext{
FFLCH - USP
} 
E ste é um dos raríssimos textos em língua geral amazônica setecentista que não se insere na categoria de dicionário, gramática ou catecismo É, na verdade, um poema, com rimas, embora tendo métrica irregular. Ele evidencia a transformação histórica pela qual já havia passado o tupi antigo, em vários níveis: morfológico, sintático, semântico, etc. Reservaremos para outra oportunidade a análise linguística do presente texto, uma verdadeira preciosidade proveniente do B rasil colonial.

O texto original não contém travessões nem aspas para assinalar a ocorrência de discurso direto. Na tradução em português, no entanto, utilizamo-los normalmente. A pontuação que utilizamos na tradução também não corresponde àquela utilizada pelo autor no original.

Algumas notas são inseridas no final do trabalho, além de uma cópia do manuscrito.

Xe remimotara rupí

E rimbäé ${ }^{1}$ icó ára acëár,

Aimocuár aõáma xe ri,

Tupã nheënga aiporacár;

Acëár abé xe retáma,

Opacatù abé xe anàma.

Paietà rocupe cöyté aiké,

Paíetá miri irúmo aicó,

Äíba porëauçúba amondé,

Aimopór catú xe recó;

Anhenupãnupã iepí,

C ecoabanhè bé akirirí2.

Päígoaçu rerecoára aicó,

Ç ocapú recé aimocuár,

Äé apëír ára iabiõo,

C amutí ý çuí aiporacár;

Äé xébo onhëengãtã
Por minha vontade

Outrora eu deixei este mundo

Para cuidar de mim

e cumprir a palavra de Deus.

Deixei também minha terra

E todos os meus parentes também.

Finalmente entrei numa ordem religiosa;

Morava com os seminaristas,

Reprimia as maldades e as misérias,

Realizava bem meu modo de viver.

Flagelava-me sempre,

Guardava silêncio de costume.

Era criado do padre superior;

Cuidava dos aposentos dele,

Varria-os cada dia,

E nchia os potes de água.

Ele comigo gritava 
Äébé xe möapyçacà.

Iabé xebo ocepymëeng

Aimocuar agoéra cecé;

Ixupé aanangài anhëeng

Aiporarà Tupã recè,

Xebo ocepymëeng mirí,

C emimotárëýma rupí

Äé Paígoaçù ogoerecó

Ç oca=púpe mbäé cetà;

Ixuí äereme aipycyrõ

Vinho catú frasco cetà,

C auacas ${ }^{3}$, marmelada abé

Aiöóc aipò meuémeué

Çupi guabirú nungára,

Açuúçuú i mbäé rí,

C uiabé oçaçáo àra cetá,

Iabé abé xe rorý mirí;

Iabé ixebo ocepymëeng,

Äé rí cecé nanhëeng.

Äé cöyté xe ri omondár

Ixébo äéreme oporandúb,

Nde çuí acuáb potàr,

Abápe, ëi, xe momorëauçúb,

Ouatár ixébo caöi),

Cëe) abé amò mbäè mirí.

Äereme, aé ixupé, cé;

Nde mbäé rí naiabyký,

Nde rocapúpe ipó oiké

Amó amó cunumi goaçù,

Nde mbäé niti apycyrõ, Aanangái=té abé amõdarõ.

Aipobäé Paí norobiár,

Xe nhëenga rupi noicó,

C öyté ybý xe pytér ucár,
E igualmente me censurava.

Assim a mim retribuía

Por eu cuidar dele.

A ele de modo nenhum respondia,

S uportava por causa de Deus.

A mim pagava pouco,

Contra a minha vontade.

Aquele padre superior tinha

Dentro de sua casa muitas coisas.

Delas então eu me apossava:

Muitos frascos de bom vinho,

C avacas e marmelada.

$\mathrm{E}$ u retirava isso bem devagar.

$\mathrm{Na}$ verdade, como um rato,

E u roía as coisas dele.

Deste modo passou-se muito tempo.

Assim como eu estava pouco feliz,

Da mesma forma ele me retribuía.

Com ele sobre isso eu não falava.

Ele, afinal, suspeitou de mim.

A mim, então, perguntou:

- De ti quero saber

Quem me prejudica.

Faltam-me vinho,

D oces também e outras pequenas coisas.

E ntão, disse a ele: -S ei lá!

Nas tuas coisas não toquei.

Nos teus aposentos entraram, talvez,

Alguns rapazes.

Tuas coisas não tomei

E de modo nenhum as furtei.

Nisso o padre não acreditou,

Não estava de acordo com minhas palavras.

Finalmente, mandou-me beijar o chão, 
Niti catù xe rerecò:

Çocapù çuí xe mocèm,

Xe remimotára agoacem.

E rimbäe oiepé Päí

Xe irunamo omaramonhang,

Çupí äé acangaíba mirí,

Äé rí xe räáräáng,

Xe roçanguán ára iabé,

Aë cöyté onhemöabäetè.

Amomorandùb Paì goaçù

Äé catú omöapyçacá;

Xe rapixàra nopöuçù,

Ixébo onhemopurãtã;

Ixébo abè ojurupoxí,

C ecoabanhè abè oicò xe rí.

Ixe roçanga opàb cöyté,

Ae; xe nde mböé potár

Iabé ipó nde xe möeté,

Ybyraçanga cöyté aïár,

Anupã çäangába rupí,

Cuiabé oiemböé mirí.

E çapyà Pai goaçú pýri ocó

Onhëengaõáma xe rí,

Xe recè Paígoaçù oicò,

Äé çupí xe mopoxi,

Xe rerecò äíb potár abé,

Anhëeng cöyté ixupé.

Aipóbäé tenhé erobiár

Paigoaçù gui; çupí ipoité,

I nhëenga tenhé eiporacár,

Äé xe recé ï abäeté,

Aipobäé taimoçupi,

Ocepiác agoéra amò Päí.

Äé amò Paí nocenõi cuáb,
Não me tratou bem,

Expulsou-me de seus aposentos.

Achei o que queria.

Um padre, outrora,

Comigo brigou;

$\mathrm{Na}$ verdade, ele era um pouco mau.

Por causa disso, ficou provando a mim

E a minha paciência o dia todo.

Ele, enfim, se enfureceu.

Avisei o padre superior;

Ele o censurou muito.

Meu confrade não teve medo,

Fartou-se muito de mim;

A mim também xingou.

De costume também brigava comigo.

Minha paciência acabou, enfim.

Disse: - Eu quero ensinar-te

assim, talvez, a me respeitar.

Tomei, enfim, um cacete;

Bati nele à medida da sua provocação.

Deste modo aprendeu um pouco.

Imediatamente foi para junto do padre superior

Para falar a meu respeito.

Comigo o padre superior discutiu;

Ele, na verdade, me denegriu,

Quis-me tratar mal também.

Falei, afinal, a ele:

- Não creias nisso,

Ó padre superior! Realmente é mentira.

À palavra dele não obedeças.

Ele foi terrível comigo.

Hei de esclarecer isso.

Um outro seminarista o viu?

E le não pôde chamar outro seminarista? 
Porque xe äé anupã ramé,

Nitì abá äéreme oiecuáb;

Niti abá xe repiác abé;

Paigoaçù cöyté xe mondó,

Xe abè coritéitè açò.

Amò Paí omimòi ucár

Oiepè payo turuçù";

Vinho çuí äé oiporacar

Opò pupé oiepè frascù,

Tapiti catù oiepè abé,

Oinong çocapùpe cöyté

Opotàr äé almoço mirí

Paietá irúmo öú aõàma,

Uataçàba aíra rupí;

Araçò äéreme xe anáma ${ }^{5}$

Äé Paí rocapúpe catú,

Aiöóc almoço, äé oröú.

C öemramè almoço ocecár,

Ogoacem nhó çurú coéra,

Amò abá recé omondár,

Nocuáb mondaçára agoéra;

Oçacem nhò äé ára pupè

Ojurù ocekendáo cöyté.

Oiepè xe rapixára

C ëe) oiucéiucéi eté,

Äé oicò cëe) rupiàra,

C ëe) xe çuí oierurè;

Aganan mirí äé Paí,

C öytè opöír cëe) çuí

Päygoaçù aretè pupé

Apycýc mirí nhò yãtã

Cöyté apokéc lenço pupé,

Aé ixupè; ëiár cëe)=etá;

Ixé çuí yãtã oiàr cöyté,
Por que, quando eu bati nele, Ninguém, então, apareceu?

Ninguém me viu também.

$\mathrm{O}$ padre superior enfim me fez ir.

E u também fui bem rapidinho.

Outro padre mandou cozinhar

Um paio grande.

De vinho também encheu

Um frasco em suas mãos.

Uma boa lebre também

Pôs dentro de seus aposentos.

Queria ele um pequeno almoço

Para comer com os padres

Durante um passeio.

Levei, então, meu amigo

para dentro dos aposentos daquele padre.

Tomei o almoço, comemo-lo.

De manhã, ele procurou o almoço;

Achou somente as vasilhas.

S uspeitou de outro;

Não soube quem foi o que o furtou.

$G$ ritou somente naquele dia;

Sua boca fechou-se, afinal.

Um colega meu

Queria muito comer doces.

Ele era caçador de doces.

D oces pediu para mim.

E nganei um pouco aquele religioso.

Enfim, partiu sem doces.

No aniversário do padre superior

Apanhei um pouco de gelo;

E ntão, embrulhei-o num lenço.

Disse a ele: - Pega os doces.

De mim pegou o gelo, então, 
Oinong algebeyra pupè.

Çacúb äépe äereme,

Oäóba guype otykýr,

Mira recé cecóreme,

I xuí aangái opöír,

Opuam apycába çuí,

Otykýtykýr pé rupí.

Ipyäíbeté xe recé,

Äé abé xeiacáiacào,

Cöyté apocàpocà cecé,

Aé i tenhé: nde putupáb,

Nde irúnamo amoiarú,

Ameengne cëe) catú.

Cöyté cëe) rurù pupé

Ainong uëena poçanga,

Äéreme amëeng ixupè,

C ecè, aé, çorý cuáb nde anga;

Ixuí öú maiabé catú,

Ouëéuëen turuçù.

Xe oiamotarëým catú,

Xe iacáiacáo eté eté,

Cëe) çuí äé oiegoarù,

Cuiabé catù äé oiemböé,

Niti iebýr oieruré,

Xe çuí cëe), ou amò mbäé

Paí goaçù cöyté xe mondé

Mbäé rerecoàra ráma,

Aicò despenseiro ràma;

Aiopói pabe) xe anàma ${ }^{5}$,

Xe rorý xe recò recé,

Nouatár ixébo mbäé.

Almoço catú äú ára iabé,

Presunto, payo, cambý ãtã,

Vinho cee) catú bäé:
E o pôs na algibeira.

Estava quente ali, então.

Debaixo de sua roupa gotejava.

Por haver pessoas (ali),

Não se livrou dele.

Levantou da cadeira,

Ficou pingando pelo caminho.

Ficou com muita raiva de mim;

Ele também ficou gritando comigo.

Entretanto, fiquei rindo dele

E disse, então: farta-te (deles).

De ti eu zombei;

Hei de dar bons doces (a ti) .

Entretanto, dentro da vasilha de doces

Pus um remédio para vomitar.

Então o dei a ele.

Disse: - Por isso, possa alegrar-se tua alma

Dele comeu a valer.

Ficou vomitando muito.

Ficou com muito ódio de mim;

Ficou gritando muito comigo.

De doces ele ficou com nojo.

Bem deste modo ele aprendeu

A não pedir de novo

Doces ou outras coisas para mim.

$O$ padre superior enfim me pôs

Como provedor;

Fui despenseiro.

Alimentava todos os meus amigos.

E u fiquei contente com minha tarefa;

Não faltava nada para mim;

Bons almoços eu comia todo dia:

Presuntos, paios, queijos,

Vinhos, bons doces. 
Xe köytè anhemopurãtã,

C oritéi abé xe kyrá,

Ambyacý nití aporarà.

C öytè naxeporëauçúb,

Ybà cëe) catù bäé,

Äéreme çupí açauçúb,

Aiotým xe righé pupé:

Despenseyro recó icatú

Äé xe tomaramo pucù.

Oiepè acajù nhò,

Aimocuár despenza recé,

Xe iöecé abé ára iabiỡ;

Paigoaçú xe mocem cöyté

Despenseiro recò çuí,

Xe äéreme aiacëó mirí.

Ambyacý çupí aiporarà,

Meza porá ixébo nocýc,

Äéreme aipyàmonketá,

Icatú amò tecò apycýc,

Infermeyro recò apotár,

Tembiú cöyténe nouatár.

Paí goaçù çuí aieruré

Infermeyro mirí recó:

Äé xe rí omäémäé,

Öacanga oimocatác nhớ

Ëí: eimocuár nde iöecé,

E potárumè amò mbäé

Ambyacý çupí oicò xe rí,

Infermeyro ráma naicò,

Xèbo ouatár tembiú mirí,

Äéreme pyaíba aicò;

Cöyté xe mbäéacý möang Iabé tembiú catù açäang Anhëeng Päi goaçù cupè,
Eu, então, me fartei muito;

Logo também fiquei gordo,

F ome não passava.

E nfim, não estava triste.

Frutas doces e boas

Amava, então, na verdade:

Enterrava-as na minha barriga.

O ofício de despenseiro é bom.

Disse eu: - Oxalá seja por longo tempo.

Um ano somente

Cuidei da despensa

E de mim também a cada dia.

O padre superior me fez sair, entretanto,

Da função de despenseiro.

E u, então, chorei um pouco;

Passei fome, na verdade,

O que era posto na mesa não me bastava.

E ntão pensei:

-S eria bom eu tomar algum ofício;

Quis ser enfermeiro.

- Comida, afinal, não vai faltar.

Do padre superior pedi

A função de enfermeiro mirim.

Ele para mim ficou olhando;

E m sua cabeça bateu, somente:

Disse: - C uida de ti mesmo;

Não queiras outras coisas

A fome, na verdade, vivia em mim.

E nfermeiro não fui.

A mim faltava um pouco de comida.

Então, eu fiquei triste.

E nfim, eu pensei em ficar doente

E, assim, boa comida eu provaria.

Falei ao padre superior: 
Paígoaçù guí mbäéacý aicó,

Naimonhangcuáb amò mbäé,

Ç acý xe çuí xe acanga nhò:

E coai) infermaria pupè,

Ëí, toimocuar nde recè.

Infermeyro çapyà acecár,

Ixébo oporandù cöytè,

E ré; mbäépe erepotár?

Indè robá pirangetè:

Çacý xe acanga Irmão guí,

Tupã recè eimocuar xe rí.

Xe inong infermeyria pupè

Çapucáia ikyrà bäé nouatàr,

C ëe) abé, marmelada abé,

Aipò xe righé oiporacár;

S ete ára pupé äépe aicò,

$\mathrm{Xe}$ righè goaçù onhepyçò.

Päí goaçù mirí erimbäé

Omanhan maiabé catú

Orè Pabe) Paí mirí recè;

Àra iabè noputuú,

Äébé oromocanëõ,

Çupí catù ára iabiõ.

Ocëár cöyté oçapatù

Ouatá meuégoaráma,

Xe roca robaké catù

Äé norocendú aõáma,

Çapatu aiaticà cöyté

Itàpyuà catù pupè.

Manhána çuí öúr ramé

Oçapatù omondé potár,

Noimoçác cuab cöyté:

Xe recé äéreme omondár,

Çupí oporabyký catú
- Ó padre superior, estou doente,

Não posso fazer nada

Minha cabeça só doi.

- Vai para a enfermaria,

Disse, - hão de cuidar de ti.

O enfermeiro logo procurei;

A mim perguntou, então:

-Dize, que queres?

Teu rosto está muito vermelho.

- Doi minha cabeça, ó irmão;

Cuida de mim, por Deus.

Puseram-me na enfermaria.

Frangos gordos não faltavam,

Doces também e marmelada.

Isso enchia minha barriga.

S ete dias ali estive.

Minha grande barriga distendeu-se.

$\mathrm{O}$ padre regente outrora

Espionava a valer

A todos nós, seminaristas;

O dia todo não descansava.

Nós o cansávamos também,

Na verdade, a cada dia.

Tirava, então, seus sapatos

Para andar devagarzinho

B em na frente de meu aposento,

Para nós não o ouvirmos.

Eu preguei os sapatos, então,

Com bons pregos

Quando vinha de espião.

S eus sapatos querendo colocar,

Não pôde despregá-los, entretanto.

De mim, então, desconfiou.

Na verdade, trabalhou muito 
Omoçàc aõáma oçapatù.

Omotëapùapú catú

Omoçác aõáma ixuí

Aiaticà agoéra oçapatú,

E reipotárpe Paígoaçú guí,

Aé, mbäé amò xe çuí,

Aicò nde nhëenga rupí.

Nitimbäè, ëí, apotár;

Moçaráitáruçù ereicó;

Tenhè xe recè emondàr,

Aé, naxe nhò iquè aicó,

Martello erepotárpe ipò,

C oipó tenaz, ou mbäé amò?

C orista recó opáb cöytè,

Penitencia cetà amonhang,

Äú ybýpe, anhenupã abé,

Amò mbäé racý açäang

C öýr Paí abaré aicò,

Aiporacàr potár xe recò.

C orista $^{6}$ pabe) aimonghetà;

Peiemböè umè xe çuí,

Pe recò peimopurãtã,

Tenhè umè peicò cunumí;

Peicò tuibäé nungára;

Aipò opotár iandé Iára.

Tuibäé äéreme peicò

Abá catú peicóramé,

Angaturàma abe toicó,

Pe irúmo auieramanhè,

C öytè Míra pemöeté,

Paigoaçù çorý nhè nhè.
Para despregar seus sapatos.

Ficou fazendo muito barulho

Para arrancá- los deles.

Pregando seus sapatos,

Eu disse: -Queres, ó padre regente,

alguma coisa de mim?

Procedo segundo tuas palavras.

- Nada quero, disse.

És um grande zombador.

Eu disse: - Em vão suspeitas de mim.

Não somente eu moro aqui.

Queres um martelo, porventura,

Ou uma tenaz ou outra coisa?

O ofício de corista acabou, afinal.

Muita penitência eu fiz,

Comi no chão, castiguei-me também;

Provei algumas coisas ruins.

Agora um senhor padre eu sou.

Quero cumprir minha missão.

Falo a todos os coristas:

- Não aprendais de mim;

Vossos ofícios realizai bem.

Não sejais meninos.

Agi como se fôsseis velhos

Isso quer Nosso Senhor.

S ede, então, velhos.

Se fordes homens bons,

Que a virtude também esteja

Convosco para sempre.

Enfim, respeitai as pessoas,

E o padre superior, sem mais, fica feliz.

Finis.

Fim. 


\section{NOTAS}

1. Tanto a consoante oclusiva glotal / quanto os hiatos são representados aqui por trema. $\mathrm{O}$ autor sistematicamente utiliza, outrossim, acento gráfico para assinalar as sílabas tônicas.

2. Cecoabanhè bé akirirí. - Guardava silêncio de costume. O tema nominal kyriri) converteu-se, na Língua Geral Amazônica, num tema verbal.

3. Cauacas, marmelada abé. - Cavacas e marmelada. C avaca é um biscoito seco, arredondado, com um dos lados revestido de açúcar de confeiteiro.

4. Oiepè payo turuçù - Um paiogrande. Paio é carne de porco ensacada em tripa de intestino grosso; linguiça de padre. Por outro lado, a forma nominal turusu somente era usada, em tupi antigo, como predicado e não como qualificativo, como vemos no texto.

5. Araçò äéreme xe anáma - Levei, então, meu amiga Anama, em tupi antigo, é 1) família, parentela; 2) parente, 3) raça, nação, pova gente do mesmo grupo ou da mesma sociedade. Na Língua G eral Amazônica do século XVIII tal palavra assume, também, o sentido de amiga Stradelli (p. 97), mostra- nos que, em nheengatu, anama também tem esse sentido.

6. Corista - segundo Moraes (p. 472), é um "religioso novo que serve no coro".

\section{BIBLIOGRAFIA}

ANÔNIMO, Diccionario da lingua geral do B rasil, que se falla em todas as villas, lugares, e aldeas deste vastissimo Estado, escrito na cidade do Pará, anno de 1771.

ARRONCHES, J oão de, O Caderno da Língua ou Vocabulário PortuguêsTupi (Notas e comentários à margem de um manuscrito do século XVIII por Plínio Ayrosa). Imprensa Oficial do E stado, São Paulo, 1935. 
SILVA, Antonio Moraes. Diccionario da lingua portugueza. Lisboa: Typographia Lacerdina, $1813,2^{a}$ edição.

NAVARRO, E duardo de Almeida, Dicionário de Tupi Antigo - A língua indígena clássica do B rasil. São Paulo, E ditora G lobal [no prelo].

STRADELLI, E., Vocabulário da Língua G eral: Português- Nheengatu e Nheengatu-Português. Revista do Instituto Histórico e Geográfico Brasileiro, 104 (158). Rio de J aneiro, 1929. 
394

TRADUÇÕES

Le Paigoasu gouvers Cocaspúpe mbià ceta'; Ixwiz äereme difyoyno. Uimb catie frapeo cella. (aurcas, mame/a) afs Ariós aigod meviemené. Gugi grabixu' nuygina; Argunverüé imbiéx, Cuenbé oxayás áva cetro', Jabe abe ne rorý mix?; Mabé ixe6o ocigymierny, A' $x i$ recé nanhéeng.

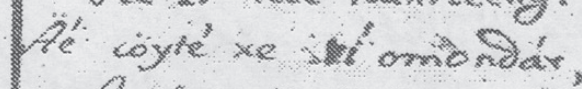

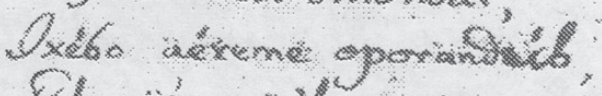
Fle sǜ acüil pordiv, - 26ápe, eí, xe momovearigúb. Onatár ixébo ranis

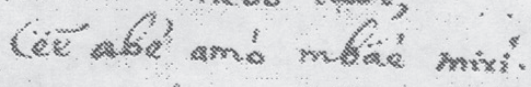
Atexeme, ax́ ixupé, cé, Rde mbáé x' naiaby ky', - Ple vocapípe jó onké Amo amo eunumigougies, Xle mbáé siti apycyma, Aanangái=té abé amodava. - Fébi xemäapycác. labe xelo orgymèng - Aimociár agoéra cecé; Oryyé anangia anlëeng, Aiporavá deypa recé, Xe6o ocgsymerang mits

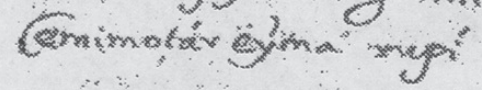

A zoobáé Sá novobiar. Xe nfeengl xyou noico, Coyré y bý xe pyrér radu,

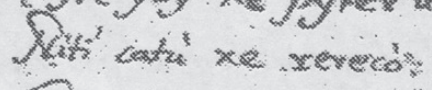
Goapid grie xe moxém, X remimirava agoacem. 


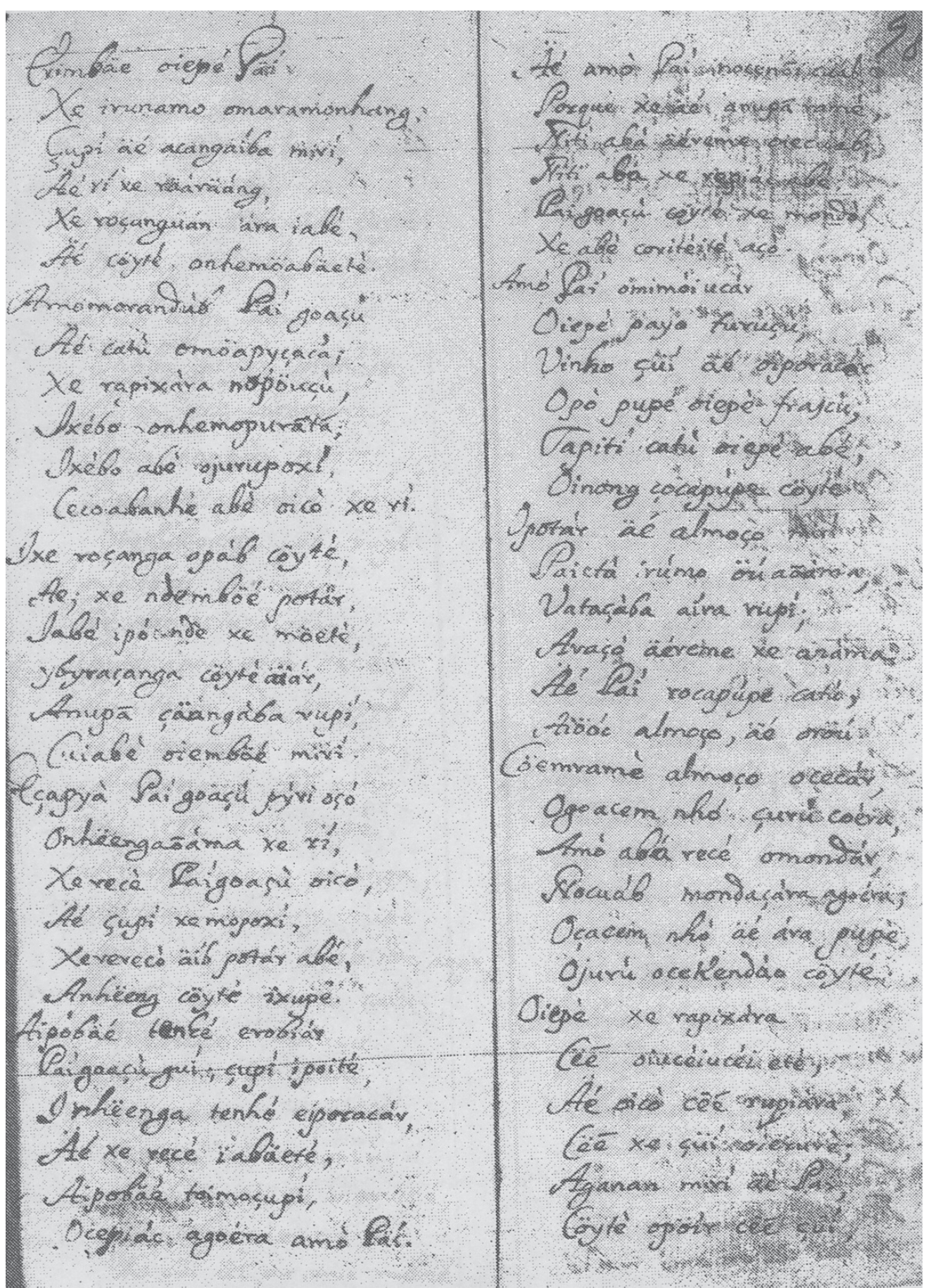




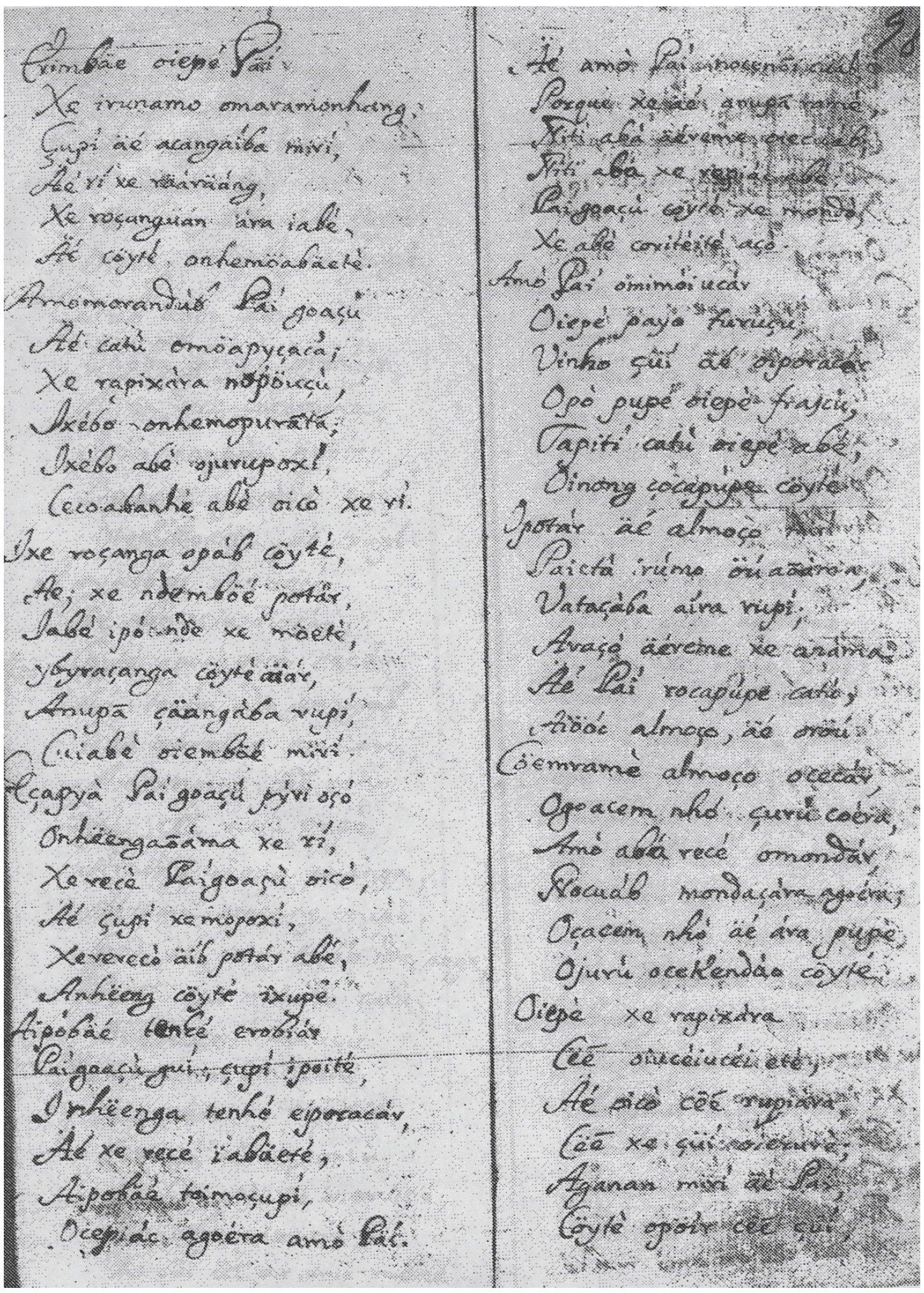




\begin{tabular}{|c|c|}
\hline 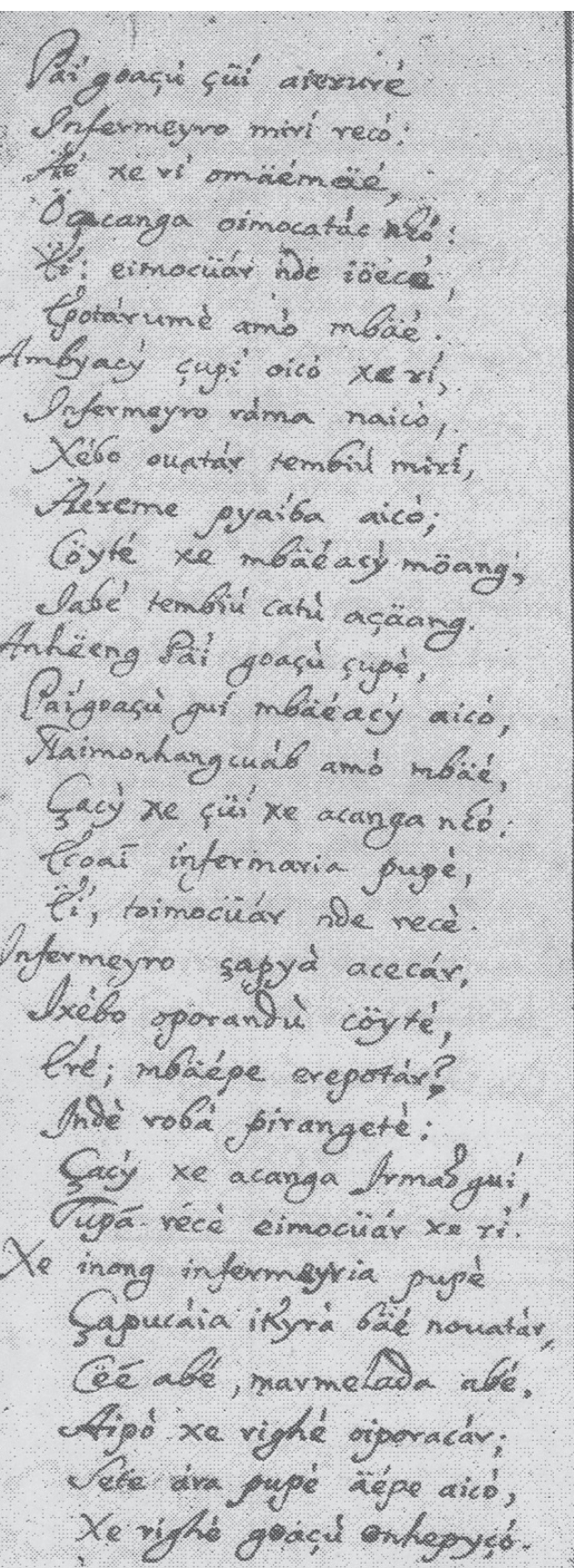 & 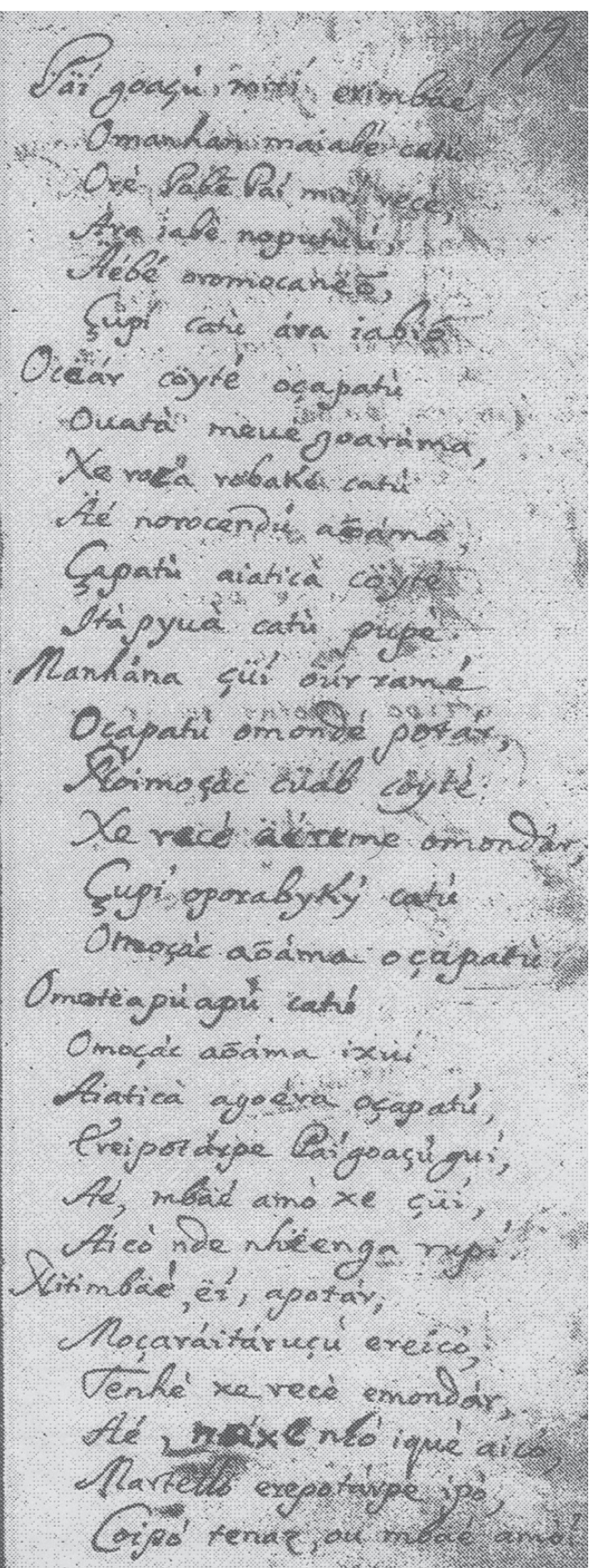 \\
\hline
\end{tabular}




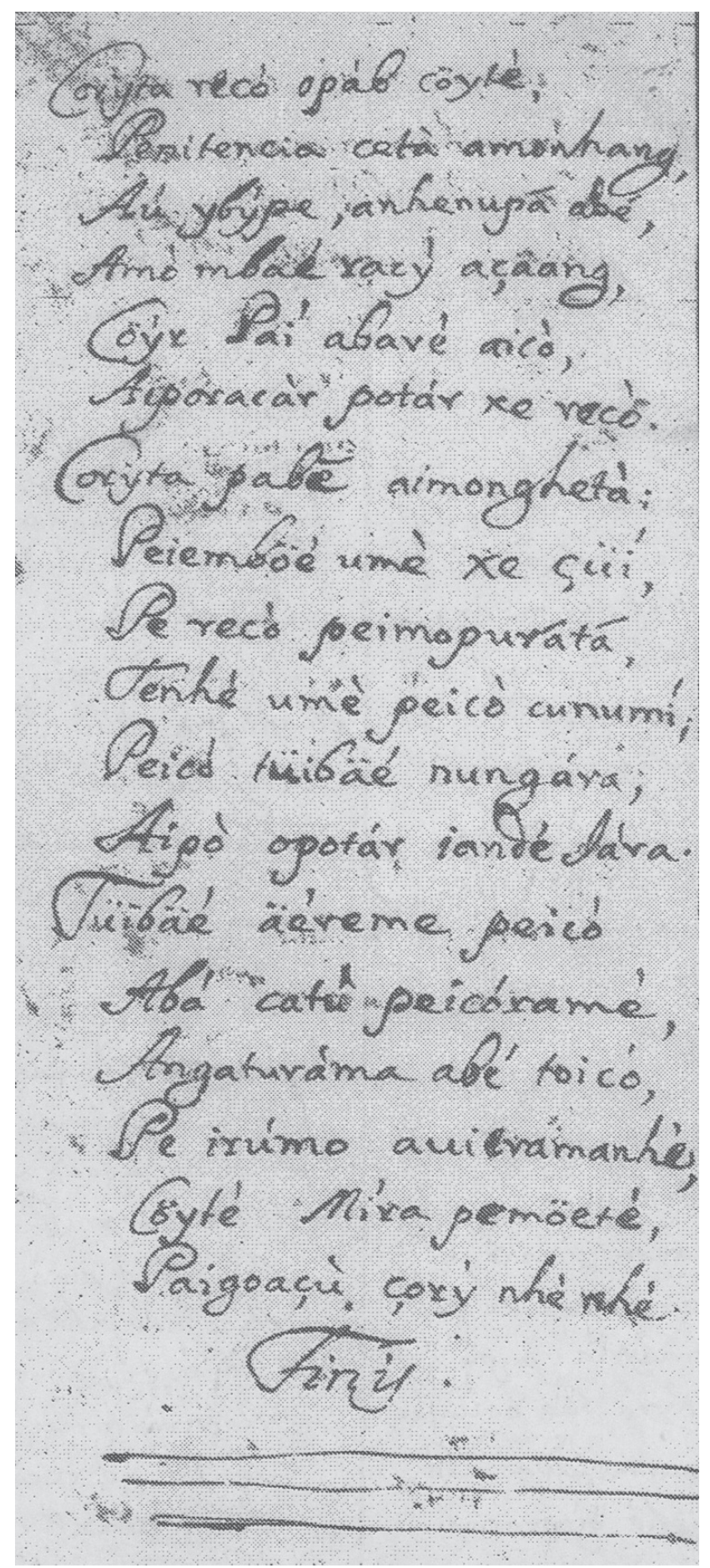

